\title{
ЕСТЕСТВЕННЫЕ НАУКИ
}

УДК 769.015.13

Е.С.Бойко, Н.Е. Бойко

\section{ЭКСПЕРИМЕНТАЛЬНОЕ ОБОСНОВАНИЕ ИННОВАЦИОННОГО ПОДХОДА К ФОРМАЛИЗАЦИИ ДВИГАТЕЛЬНОЙ ДЕЯТЕЛЬНОСТИ ЧЕЛОВЕКА}

Приведены результаты экспериментальных исследований, позволяющие внести некоторые уточнения и дополнения в теорию управления движениями (на примере спортивных упражнений).

Ключевые слова: предметная деятельность, компьютерно-инструментальные технологии регистрации движений, инновационный подход, теория управления движениями, вариационная психобиомеханика двигательной деятельности.

Исследование двигательной активности человека издавна занимает особое место среди наук о живом организме и привлекает внимание многочисленных учёных. Это обусловлено той ролью, которую играет двигательная деятельность в жизни человека. Именно от неё зависят возможности активного взаимодействия с окружающей средой и, в частности, совершенствование в спортивных движениях.

В многочисленных моделях, предложенных для формализации движений человека, ещё не найден, а только ищется адекватный сложной исследуемой реальности язык описания. Пока этот язык в большей степени описательный, чем объяснительный, и это вполне естественно, поскольку исследователям открывается огромная новая область, соизмеримая по сложности с тем, что классическая наука называет психикой, оставляя на периферии своего внимания моторику.

Последняя интерпретировалась как само собой понятная механическая или техническая часть жизни, которая, однако, сама является исключительно сложной системой и, что самое главное, находится в непрерывной диалектической связи с психикой. Еще И.М. Сеченов писал: «Смеется ли ребенок при виде игрушки, улыбается ли Гарибальди, когда его гонят за излишнюю любовь к родине, дрожит ли девушка при мысли о любви, создает ли Ньютон мировые законы и пишет их на бумаге - везде окончательным фактом является мышечное движение» [3, с. 42].

Мы придерживаемся взгляда Н.А.Бернштейна [1], согласно которому при двигательной деятельности человека (в том числе и в спортивных упражнениях) формируется одномоментный пространственный образ выполняемого действия.

Образ - целостное интегральное отражение действительности, в котором одновременно представлены основные перцептивные категории (пространство, форма, движение) и важнейшей функцией которого является управление двигательными действиями (наличие обобщенного представления или же плана предстоящих действий, конкретной спецификации действий и детальной программы их исполнения).

Пространственная структура образа складывается в результате двигательных действий человека благодаря преобразованию биодинамической мозаики взаимодействия аппарата человека (спортсмена) с внешним силовым окружением в психическую (чувственную) ткань пространственного образа.

Эти две стороны деятельности человека взаимно изменяются и развиваются, и здесь требуется выявление их взаимовлияния и взаимопроникновения, ибо, познав закономерности их взаимодействия, можно с большей уверенностью говорить и отдельно об организации этих двух компонентов жизнедеятельности организма человека.

Мы предполагаем, что использование новейших компьютерно-инструментальных технологий, позволяющих регистрировать мельчайшие «интимные» отклонения в харак- 
теристиках двигательных действий, и специального компьютерно-математического анализа получающихся в этом случае огромных массивов исходной информации позволит внести некоторые уточнения и дополнения в модель двигательного действия.

Целью исследования является повышение эффективности методики совершенствования предметной деятельности человека (на примере физических упражнений) на основе разработки методов определения количественных и качественных перестроек, возникающих в процессе обучения в целостной структуре двигательных действий.

Разработано новое средство для изучения двигательной деятельности - биокибернетический микросинтез и системный анализ характеристик движений, основанный на выделении, анализе, качественной и количественной оценке факторов, отражающих эффективность функционирования механизмов управления движениями и саморегуляции (включая высшие разделы психики).

В связи с этим была создана батарея компьютерно-инструментальных информационных систем, позволяющих регистрировать незначительные по величине отклонения (микроразбросы) в параметрах двигательных действий в спортивных упражнениях, ибо только в функции разбросов могут проявиться закономерности организации и построения движений [2].

На основании анализа вариационных и автокорреляционных кривых характеристик движений, спектров параметров двигательных действий, корреляционного и механикоматематического анализа выявлены закономерности процессов развёртывания движений в беговых и прыжковых упражнениях, метаниях, психомоторных тестах деятельности сердечной мышцы [2].

Обнаружено, что, во-первых, эти процессы действительно представляют собой случайные процессы. Так, в качестве примера на рис.1 показаны реальные значения времени пробегания одинаковых отрезков дистанции, скорости бега и ускорения общего центра тяжести (ОЦТ) тела при пробегании дистанции 30 м с ходу мастером спорта международного класса В.Мальчугиным. Видно, что характеристики бега не являлись величинами постоянными, а непрерывно изменялись по ходу дистанции, хотя спортсмен бежал с установкой на постоянную максимальную скорость. В данной попытке спортсмен показал результат 2,85c, развив среднюю скорость 10,52 м/с, которая, однако, изменялась по дистанции от 9,91 до $11,45 \mathrm{~m} / \mathrm{c}$ со среднеквадратическим отклонением $\sigma=0,286 \mathrm{~m} / \mathrm{c}$ и разбросом в $1,54 \mathrm{~m} / \mathrm{c}$.

Данный график представлен со 100-кратным усреднением. В действительности значения скорости, ускорения и времени пробегания фиксировались через каждые 0,5 см дистанции (в представленном примере было получено по 6000 значений исследуемых параметров).

Здесь мы подтверждаем мнение великого русского физиолога Н.А. Бернштейна о том, что в результате действия миллионов сложнейших, переменных, наперед не предусмотренных фактов психобиомеханическая ткань конкретной двигательной деятельности так же уникальна, как отпечаток пальца человека.

Н.А.Бернштейн, первым чётко обозначивший задачу управления движениями, писал: «Движение возможно лишь при условии тончайшего и непрерывного, непредусматриваемого заранее согласования центральных импульсов с явлениями, происходящими на периферии тела» [1].

Во-вторых, выявлено, что в этих процессах заключены две категории процессов: стационарные и нестационарные.

Стационарные процессы проявляются в параметрах движений как процессы, ряды характеристик которых по своим значениям приближаются к гармоническим колебательным контурам; гистограммы распределения значений параметров движений стремятся принять вид кривых нормального распределения, графики спектров характеристик двигательных действий прижимаются к оси абсцисс, характеризуя незначительные 

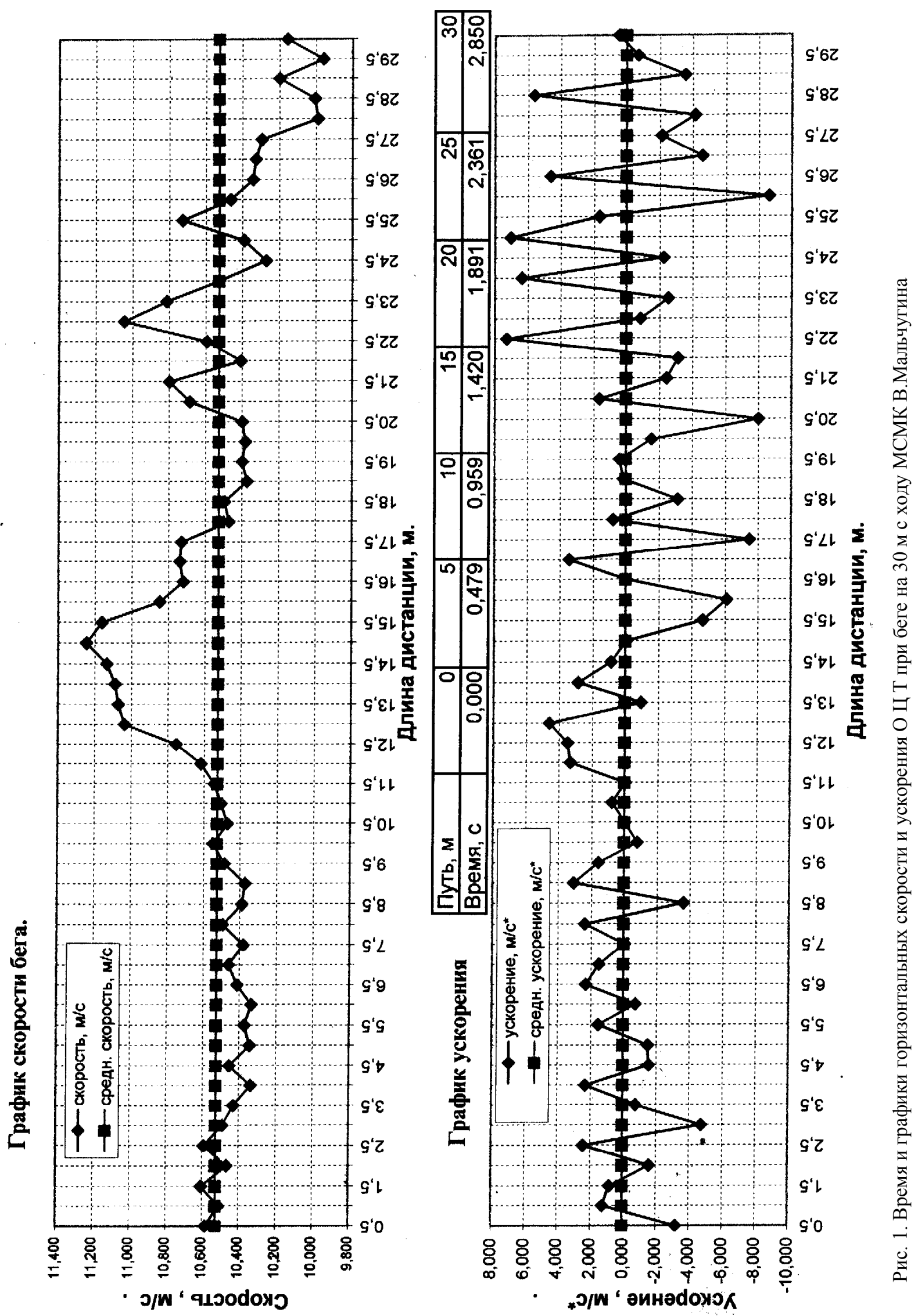
мощностные и энергетические затраты в этой зоне движений, кривые их автокорреляционных функций быстро затухают, параметры систем функционального обеспечения - минимальные [2].

Обнаружено, что практически во всех спортивных движениях - при удержании постоянных циклических режимов движений [2, гл. 3,4], циклических психомоторных движениях [2, гл. 6], переходных циклических режимах движений [2, гл. 3, 4], ациклических двигательных действиях [2, гл. 6], сложнокоординационных движениях [2, гл. 3-5] биосистема человека стремится организовать силовые взаимодействия с внешними силами с характеристиками гармонического колебательного процесса.

Конечно, эти взаимодействия имеют свои определенные черты в каждом виде упражнений: в постоянных циклических движениях - приближение к чистой синусоиде (в представленном на рис.1 примере это примерно первая треть дистанции бега спортсмена), в переходных движениях - следующие друг за другом положительные полупериоды синусоид, в ациклическом режиме - первый полупериод синусоиды, в сложнокоординационном упражнении - накладываемые друг на друга положительные полупериоды синусоид, образуемых в каждой из плоскостей пространства [2].

Стационарные процессы характеризуют собой равновесные, устойчивые движения спортсменов, которых они достигли в результате двигательной деятельности за предыдущие периоды обучения, и можно сказать, что стационарный процесс - это изученная, детерминированная часть «моторного поля» (Н.А. Бернштейн) человека, где им уже в результате тренировок (адаптации) выработаны, если так можно выразиться, «консервативные» взаимосвязи и динамическое равновесие между психической и биодинамической составляющими пространственного образа выполняемых движений (здесь мы имеем уже «определенный четкий» образ активного действия человека в окружающем его силовом пространстве).

Выявлено, что стационарность (гармоничность) является наиболее экономичным характером взаимодействия человека с окружающей средой: в одни моменты (на положительных полупериодах регуляции движения) импульсно расходуется энергия для преодоления сопротивления силового поля, в другие (на отрицательных полупериодах) используется этот же потенциал силового поля, которое при отрицательном ускорении начинает само «разгонять» двигательный аппарат спортсмена. Адаптация - это выработка умения согласовывать импульсное переключение акцентов мышечных напряжений с главными моментами двигательных заданий при эффективном использовании энергетического потенциала внешнего силового поля.

При такой организации биосистема человека функционирует с минимальными затратами энергии в единицу времени, достигая главной цели самоорганизующихся систем - надежности и устойчивости жизнедеятельности.

Действительно, биосистема человека не может позволить себе роскошь сжигать энергию постоянно, и эволюция привела к созданию таких рациональных биомашин, деятельность которых основана на импульсных расходах энергии: в определенные моменты сопротивление силового поля преодолевается за счет усилий, а в другие моменты для расслабления мышц и уменьшения расходования биоэнергии используется энергетической потенциал этого же внешнего силового поля, которое начинает само «разгонять» двигательный аппарат спортсмена.

В сформированном образе биодинамическая и психическая составляющие представляют в данном случае как бы две стороны единого целого. В формировании пространственного образа выполняемых спортивных упражнений ведущую роль играют биодинамические характеристики двигательной деятельности спортсменов, конкретная мозаика функционирования активных элементов мышечного аппарата - мышц. В сформированном образе ведущее положение занимают высшие психические образования - чувственная 
ткань [1]. При построении движений осуществляется обратный перевод, т.е. в высших психических центрах спортсмена чувственная ткань трансформируется в конкретную иерархию координационных отношений различных элементов мышечной системы и в определенное биодинамическое взаимодействие спортсмена с внешними силами.

Это равновесие - гармоничность (ядро системы) - есть всего лишь временной срез кривой изменения степени стационарности в случайных двигательных режимах обучающихся, а динамика развития заключается в том, что в реальных условиях процесса обучения нервно-мышечная система начинает функционировать в двух режимах: стационарном и переходном (нестационарном).

Характеристики нестационарного процесса - это параметры двигательных действий учащихся, пытающихся прорваться в еще неизведанную и при этом более интенсивную часть силового пространства, где на их желание развить большие скорости и ускорения внешняя среда отвечает динамически адекватным проявлением значительных сил, действующих против движения. Для выхода на более высокий уровень действий необходимы поправки в психической составляющей двигательного образа, именуемые в практике настройками, самоустановками, волевыми усилиями человека, которые формируются методической направленностью педагогического процесса обучения.

Обнаружено, что в этом случае спортсмен переходит на движения, характер которых можно представить как наложение друг на друга уже изученного гармонического и нового вынуждающего колебательных контуров, проявляющихся в характеристиках двигательных действий как режим вынужденных колебаний (на рис. 1 - скорость и ускорение с 10 го по 30-й метр дистанции бега спортсмена).

Высшие уровни управления движениями (психическая ткань) через систему обратных связей стремятся консолидировать их совместную работу, сдвигая, например, друг относительно друга периоды этих колебательных контуров, накладывая друг на друга их амплитудные значения, с тем чтобы выработать новые стационарные режимы (гармонический контур колебания), которые характеризуются более высокими биомеханическими характеристиками выполняемых упражнений.

Гистограммы распределения характеристик движений начинают отличаться от нормального распределения: сдвигаются по оси параметров в сторону их больших значений, вытягиваются вверх (растут амплитуды и частоты в интервалах распределения биомеханических показателей), сужаются у основания (уменьшаются число интервалов распределения и среднеквадратические отклонения характеристик). Резко увеличивается выделяемая обучающимся мощность, которая в спектрах характеристик движений концентрируется в зоне более низких частот изменения параметров двигательных действий, кривые автокорреляционных функций параметров долго не затухают, увеличивается активность мышц, являющихся ведущими элементами межмышечной координации, и уменьшается активность мышц, играющих в движениях второстепенную роль [2].

Опыты показали, что в процессе совершенствования двигательных действий, протекающих в вынужденных контурах характеристик движений (адаптации), меняется в первую очередь биодинамическая составляющая пространственного образа движений, которая по своим параметрам вновь приближается к стационарным режимам двигательных действий и детерминирует определенные эффективные преобразования в психической (чувственной) составляющей двигательного образа.

В сформированном в результате активного обучения новом образе движений психическая и биодинамическая его составляющие вновь находятся в динамическом равновесии, но при этом психическая (чувственная) ткань образа трансформируется в стационарный двигательный режим, происходящий с большими скоростями, меньшими затратами мощности и энергии. 
Обосновано, что непрерывность процесса обучения движениям обеспечивается тем, что в двигательных структурах всегда присутствует определенным образом построенная предыдущим обучением динамически устойчивая композиция (стационарный процесс), являющаяся базисом, на котором строятся реальные двигательные режимы, воспроизводимые в процессе обучения, и который непрерывно развивается. Развитие системы движений происходит по спирали, с каждым витком которой связи между элементами всё больше укрепляются, а ядерный элемент всё в большей мере отражает всю систему в целом.

На рис. 2 представлена условная спираль пространственно - временного непрерывного формирования движений. На низших витках спирали, на начальных стадиях обучения двигательной деятельности, где у обучающихся создается первое представление о двигательных действиях, формируются установки на обучение им, осуществляется педагогико-методическая деятельность по овладению занимающимися основами техники и ритмом движений, происходит формирование начального режима выполнения движений.

Гистограммы распределения параметров движений характеризуются низкими значениями амплитуд мод, отрицательными величинами эксцессов, большим количеством интервалов, что свидетельствует о большом разбросе и вариативности характеристик движений и значительном отличии гистограмм от кривых нормального распределения. В спектрах характеристик движений спектральная плотность распределяется хаотично на всех частотах изменения характеристик - выделить стационарную составляющую колебательных процессов динамических рядов параметров движений невозможно. Кривые автокорреляционных функций характеризуют двигательные действия как случайный процесс, в котором выделить стационарную составляющую также затруднительно.

На каждом витке спирали спортивного совершенствования переходные двигательные режимы лежат в определенном диапазоне (рис.2). Левой границей диапазона является построенный спортсменом на предыдущем витке обучения стационарный двигательный режим, а правой - предельный рекордный режим движений, на который спортсмен может выйти при самых удачных обстоятельствах на данном витке его спортивного совершенствования. Этот предельный двигательный режим спортсмена лимитируется общими законами регулирования, такими как законы устойчивости и надежности. А это означает, что параметры двигательных действий спортсменов на каждом витке спирали совершенствования не могут отклониться от параметров устойчивого состояния (от стационарного режима) больше чем на определенную величину.

Кроме того, выявлено, что чем дальше параметры движений отклоняются от стационарного процесса, тем сильнее нарастает импульс к их восстановлению. Именно поэтому, как мы можем наблюдать в кривых реальных характеристик двигательной активности спортсменов (рис. 1, 10-20-й метры дистанции, пробегаемые спортсменом), набираемые в отдельные моменты максимальные значения параметров редки и удерживаются короткое время [2].

Так, на рис. 1 видно, что спортсмен с 11,5 до 14,5 м дистанции бега резко нарастил скорость бега с 10,54 до 11,45 м/с, достигнув, вероятно, своего скоростного предела. Затем кривая скорости бега стала резко падать до 10,42 м/с. Следующий участок - явно выраженный режим вынужденных колебаний, где на стационарный бег спортсмена (1-10-й метры дистанции) наложился вынуждающий колебательный контур характеристик движений, вызванный установками спортсмена на увеличение скорости бега. Удивительно, что при беге длительностью всего 2,85 с произошло столько событий. 


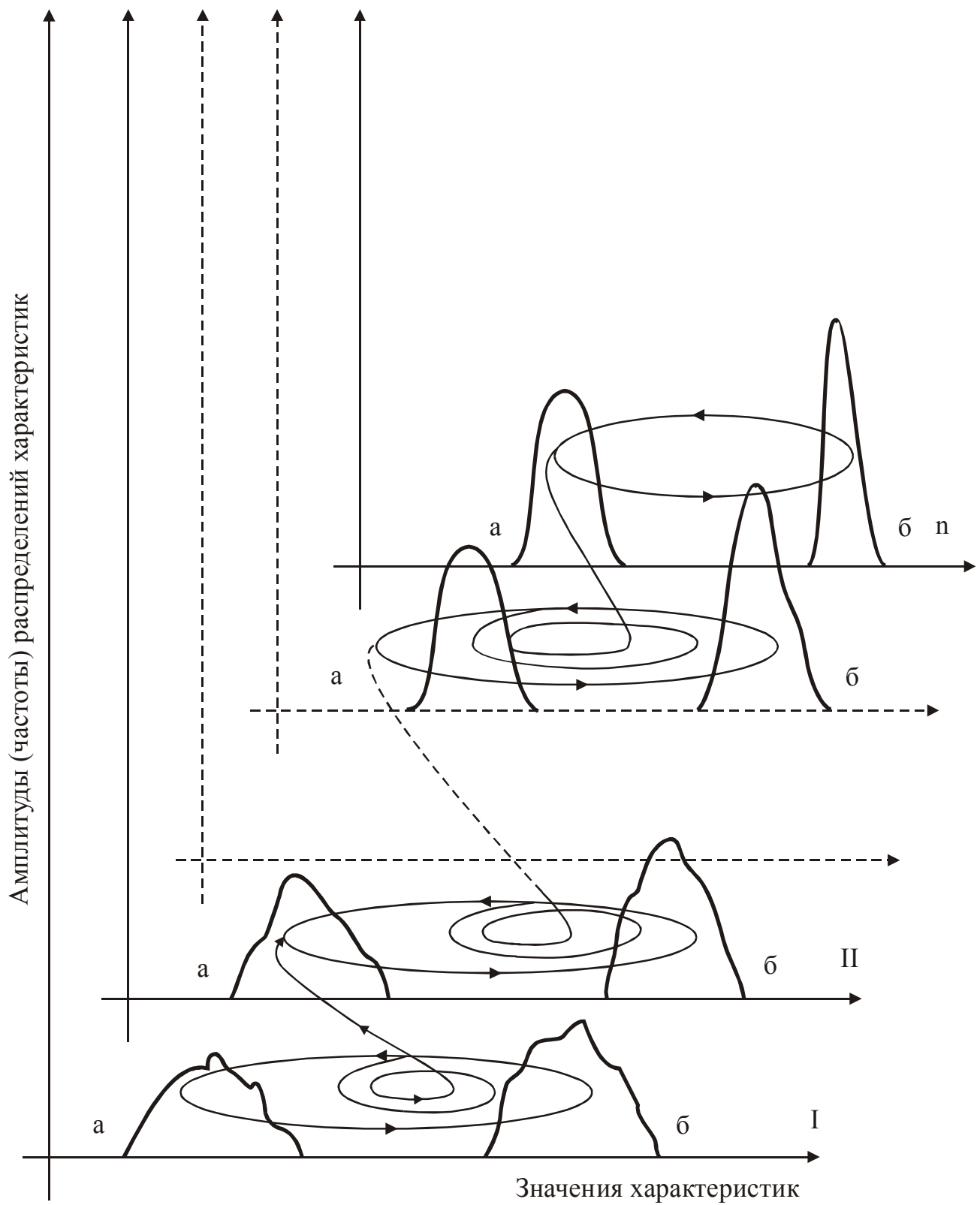

Рис. 2. Условная спираль процесса непрерывного совершенствования характеристик двигательных действий спортсменов: 1 - n - витки спирали (от начальных этапов обучения (1) до высшего спортивного мастерства (n)); а - стационарный двигательный режим; б - предельно возможный двигательный режим для данного витка спирали совершенствования движений

Выявлено, что на каждом витке спирали двигательного совершенствования двигательные действия спортсменов представляют собой случайные колебательные процессы, в которых на стационарные процессы накладываются действующие долго, но незначительно нестационарные процессы и более мощные нестационарные процессы, существующие короткое время.

Через двигательные действия, реализующие в движениях соответствующие этим условиям двигательные задания, постепенно формируется пространственный образ выполняемых движений, в первую очередь его чувственная, психическая составляющая, которая через все более совершенную биодинамику взаимодействия занимающихся с внешним силовым полем (в ней все больше проявляются и растут показатели стационарных двига- 
тельных режимов) формирует новую стационарную составляющую психической ткани пространственного образа движений.

В предложенной модели спирали непрерывного обучения движениям это завершение определенного её витка, откуда по той же схеме, в динамической борьбе и совместном совершенствовании психики и биодинамики, пойдет новый виток спирали роста спортивного мастерства.

Исследования позволили наметить контуры нового научного направления - антропоцентрической вариационной психобиомеханики, сущность которой состоит в изучении вероятностных свойств двигательной активности человека как случайным образом разворачивающихся во времени и пространстве психобиомеханических процессов, представляющих собой способы решения двигательных задач, формируемых в сознании личности. Причем возникающие разбросы в параметрах движения рассматриваются как характеристики процессов построения образа выполняемых движений, разработки плана двигательных действий, детальной программы его выполнения и процесса непосредственного взаимодействия двигательного аппарата с внешней средой.

Опыты показали, что математические показатели и выражения (интервалы и частоты гистограмм распределения параметров двигательных действий, их эксцессы, асимметрии, среднеквадратические отклонения, моды и их амплитуды, значения спектральной плотности и их распределения, значения автокорреляционных функций и т.д.) в научном сознании и практике приобретают философский и психобиомеханический смысл и становятся количественно-качественными характеристиками внешней и внутренней структуры организации и управления нервно-мышечным аппаратом человека, эффективности выполняемых двигательных заданий и применяемых при обучении движениям педагогических приемов.

В заключение хотелось бы отметить, что процесс формирования двигательной деятельности человека имеет много общего с солнечной активностью: дневной и ночной свет есть наложение друг на друга световых волн с различными амплитудно-частотными характеристиками; преобладание в спектре более жестких ультрафиолетовых волн формирует светлое время суток, а преобладание инфракрасных волн - ночной свет.

Все в природе адаптируется к солнечной активности, стремясь функционировать с параметрами гармонического процесса, который при минимальном расходовании энергии позволяет обеспечить надежность и устойчивость жизнедеятельности. Так же и мозг человека с разных уровней управления посылает по двигательным нервам управляющие команды. С более высоких - более мощные, к которым биосистема человека адаптируется так, как было рассмотрено выше (подчиняясь законам природосообразности).

Данные исследований во многом подтверждают выводы, сделанные еще в 20-30-е годы прошлого столетия нашим земляком, замечательным и надолго забытым ученым А.Л.Чижевским. Только в 70-е годы была издана его уникальная книга «Земное эхо солнечных бурь», в которой он пишет: «И если кто-то зло и остро смеется над потугами связать мир астрономических и биологических явлений, то в глубине человеческого сознания уже много тысячелетий зреет вера, что эти два мира, несомненно, связаны друг с другом».

\section{СПИСОК ЛИТЕРАТУРЫ}

1. Бернштейн, Н.А. О построении движений / Н.А. Бернштейн.- М.: Медгиз, 1947.-262 с.

2. Бойко, Е.С. Экспериментальная психобиомеханика двигательной деятельности человека (на примере физических упражнений): практикоориентир. моногр./Е.С.Бойко.- Брянск: Изд-во БГУ,2004. - 248 с.

3. Сеченов, И.М. Избранные философские и психологические произведения/ И.М. Сеченов. - М.: Гос. издво полит. лит., 1947. - 192с. 